\title{
Exploring the impact of social inequality and poverty on the mental health and wellbeing and attainment of children and young people in Scotland
}

\author{
Abstract \\ The poverty-related attainment gap is an internationally recognised problem. There is \\ growing recognition that it cannot either be understood or addressed without taking \\ cognisance of children's mental health and wellbeing. The focus of this conceptual paper \\ is to examine the impact of social inequality and poverty on the mental health and \\ wellbeing and attainment of children and young people in Scotland through the lens of \\ resilience. Whilst not a 'state of the art' literature review, a systematic approach was \\ adopted in the selection of the literature and in the identification of themes to emerge \\ from it. A range of risk and protective factors at the individual, social, societal and \\ political levels emerged as impacting on the mental health and wellbeing and attainment \\ of children living in poverty and three important mediating variables are the negative \\ impact of social stratification and adverse childhood experiences and the positive impact \\ of a supportive adult. Schools alone cannot solve the problem. The findings revealed that \\ there is a need to build a strong infra-structure around families and schools and to \\ examine how economic, social, health and educational policy interact with each other as \\ a starting point in addressing the problem, supported by inter-disciplinary research.
}

\section{Keywords}

Poverty, attainment, mental health and wellbeing, social stratification, Adverse Childhood Experiences, Child and Adolescent Mental Health Services (CAMHS) 


\section{Introduction}

This conceptual paper is exploratory in nature and seeks to understand an issue of global concern - the impact which social inequality and poverty exert on the mental health and wellbeing and attainment of children and young people in Scotland, placing this with a broader international context.

Whilst not a 'state of the art' systematic literature review, the study draws from an extensive multi-disciplinary and international literature. Jesson, Matheson \& Lacey (2011) argue that systematic reviews are not always appropriate in the social sciences when undertaking multidisciplinary enquiry, therefore the study does not attempt to provide a comprehensive overview of the respective fields but, rather, draws on the literature to illuminate the issues.

The paper represents one of four themes to have emerged from the study mental health and wellbeing, which, it was considered, merited a theme in its own right. The other themes identified were the macrosystem (public policy, cultural values and social cohesion); the nature and strength of social networks and support systems (related to social capital); and, achievement motivation and aspirations (related to cultural capital). The themes, while distinctive in their own right, are also strongly inter-connected. For example, the nature and strength of social networks and support systems exert a significant effect on the mental health and wellbeing of children and young people (World Health Organisation, 2016).

The paper does not set out to critique the literature or the reliability of the methodological approaches adopted by researchers in the respective fields nor does it set out to provide 'solutions' to this complex problem (although it does explore the implications of the findings to emerge from the analysis). Rather it seeks to present to the reader the nature of the relationships between social inequality, poverty, mental 
health and wellbeing and attainment (whether direct or indirect) and the mediators of these relationships (for example, maternal distress) which were identified from the analysis. This acts as a prelude to a more holistic discussion which focuses on the implications of what has been found, at that point critiquing some of the concepts to have emerged - such as Adverse Childhood Experiences (ACEs).

The initial discussion to follow serves to contextualise the problem and outlines its nature - why we should be concerned.

\section{The Nature of the Problem}

There has been a growing recognition internationally that the gap in attainment associated with poverty cannot either be understood or addressed without taking cognisance of children's and young people's mental health and wellbeing (Gomendio, 2017; OECD, 2018b; Schleicher, 2014, UNICEF Office of Research, 2016). Such an approach requires an holistic understanding of communities, families and children recognising that poverty arises as a consequence of inequalities between and within societies (Wilkinson \& Pickett, 2010).

The 16 United Nations Children's Fund (UNICEF) goals for sustainability (UNICEF Office of Research, 2017, p.7) provide a moral imperative to address this problem. According to the United Nations, one in five children in rich countries live in relative income poverty and one in three European children are deprived in two or more ways ${ }^{\text {i }}$. The Joseph Rowntree Foundation (Wolff, Lamb \& Zur-Szpiro, 2015) defines relative poverty as: 'living at a level of income that does not allow one to take part in the normal or encouraged activities for one's society' ("What is poverty"). Adolescent mental health issues are becoming more common; and, even in the 
highest-performing nations, one in five fifteen year-olds do not reach what are regarded as basic educational standards (UNICEF Office of Research, 2017).

It has been established that outcomes for children on a range of measures relating to education, health and life satisfaction are poorer for children living in unequal societies (UNICEF Office of Research, 2016, 2017; Wilkinson \& Pickett, 2010). The disparities in attainment between children who are most and least disadvantaged remain relatively constant over time and have a lasting impact on life opportunities, such as having access to further and higher education (OECD, 2018a; UNICEF Office of Research, 2010; UNICEF Office of Research, 2017).

Within the United Kingdom (UK), concerns have been raised about a more individualistic (in the sense of a focus on a 'successful life' rather than a contribution to the life of others) and selfish society (Layard \& Dunn, 2009). Young people feel pressured to fit in with the expectations of society and those living in poverty feel less optimistic, less useful and have more of a sense of being a failure than their peers (Ayre, 2016).

The most recent findings to emerge from the UK-wide millennium cohort study (Patalay \& Fitzsimons, 2018) identify both age-related and gender patterns. Mental health for many children, particularly girls, declines from age 11 to age 14 and there is a stronger relationship between wellbeing and mental health in girls than in boys. The data suggests there is an association between low socio-economic status ${ }^{\mathrm{ii}}$ in girls and depression at age 14, when account is taken of mental health at age 11, but not for boys. Being overweight, bullied and having poor interpersonal relationships are all associated with higher levels of depression in both genders. The authors advocate a more differentiated approach to identifying the needs of girls and 
boys, which takes account of the wider circumstances of the child, and better integration with schooling.

Gendered patterns of response are also evidenced in international data with UNICEF reporting twice as many adolescent girls reporting mental health symptoms than boys (Bruckauf, 2017). This is paralleled with increasing concerns at a global level about mental health in general and the mental health of children and young people in particular (Bruckauf, 2017, World Health Organisation, 2016) with devastating repercussions: 'Mental health problems kill more young people than any other cause around the world' (Patel, Sheckar, Lund, Thornicroft, Baingana \& Bolton, 2018).

At this point, it is of value to reflect on the nature of some of the concepts under question, in particular, the concepts of mental health and wellbeing.

\section{Conceptualisations of mental health and wellbeing}

There is an extensive literature devoted to mental health and wellbeing and a plethora of terms such as wellbeing, subjective/psychological wellbeing, mental health and mental illness/conditions/issues/problems/disorders/symptoms/distress which are often used synonymously and interchangeably, being defined in different ways in different contexts.

With regard specifically to children and young people, mental health, as expressed through the World Health Mental Action Plan (2013-2020), focuses on developmental aspects such as having a positive sense of identity, social and emotional capacities and an aptitude to learn and acquire an education (World Health Organisation, 2013), thus emphasising a capability perspective. However, as indicated above, mental health also has more negative connotations with the term mental illness 
tending to refer to a diagnosable psychiatric condition and mental health disorder applied to more severe, enduring conditions, such as eating disorders (Murphy, 2016).

Wellbeing, according to the Mental Health Foundation Scotland, is described as 'how people feel and how they function, both on a personal and a social level, and how they evaluate their lives as a whole' (Mental Health Foundation, 2015, "What is wellbeing", para. 1). This definition emphasises the relationship between the inner (emotions) and the social self and the reflective aspect of mental health (evaluation), which implies a degree of emotional intelligence (see Goleman, 1996).

The Children's Society makes a distinction between subjective and psychological wellbeing: subjective wellbeing has both affective and cognitive aspects and is described as comprising two elements - life satisfaction and experience of positive and negative emotions at a specific time - whereas psychological wellbeing is regarded as being associated with meaning, purpose and engagement (Ayre, 2016). The latter is further exemplified as comprising aspects such as selfacceptance, personal growth, autonomy and personal relationships (The Children's Society, 2018).

Wellbeing, from a capabilities perspective (Smith, 2018), is related to the extent to which an individual is able to realise their potential across a range of domains, for example, their sense of affiliation towards others. The capabilities perspective (drawing from Nussbaum's capability approach) is that 'people have “functionings" which give their lives meaning and value,' underpinned by capabilities and the freedom to be able to exercise them (Smith, 2018, p.3).

The above discussion can only 'scratch the surface' but what is evident is that the distinctions between mental health and wellbeing are not clearly delineated leading to a lack of conceptual clarity around the concepts and their use. 
Having examined the nature of the concepts, we now explore the prevalence of mental health disorders in children and young people in Scotland, how Children and Adolescent Mental Health Services (CAMHS) are experienced and perceived by children and young people themselves and the response of the Scottish Government to promoting positive mental health in this age group.

\section{The mental health of children and young people in Scotland}

It is estimated that around $10 \%$ of children and adolescents in Scotland have a diagnosable mental health disorder (Murphy, 2016), representing a 13.5\% increase in referrals to CAMHS over a two-year period from 2013-2015. However, the prevalence of severe mental health difficulties in 11-year old children (as measured by the Strengths and Difficulties Questionnaire score ${ }^{\mathrm{iii}}$ and rated by their parents) is less for children in Scotland than within the other nations of the UK with a quarter fewer Scottish children represented in the statistics (Gutman, Joshi, Parsonage, \& Schoon, 2015).

4,222 children and young people started treatment at CAMHS in Scotland in the quarter ending in Dec 2016, 82.5\% of whom commenced treatment within 18 weeks of referral (NHS Information Division, 2017). However, waiting times vary considerably across Scotland with fewer than half of those referred being seen within the recommended period in a few local authorities (Murphy, 2016). Concerns are expressed about the availability and geographical location of in-patient services with some children being located far away from their homes, making it more likely that they will have a delayed recovery and putting additional strain on their families (Murphy, 2016).

There is also concern about the number of children and adolescents being referred to non-specialist units (77 admissions of 66 young people in 2016-2017 of whom 57\% were admitted for a week or less) but there has been a substantial reduction in admissions 
of this nature since 2015-2016 (Murphy, pp. 18-19). The Scottish Government Report 'Supporting Children's Learning' (Scottish Government, 2016b) - raises concerns that the needs of children and adolescents with mental health difficulties are not being adequately met, citing a lack of a clear definition of mental health amongst practitioners and a lack of awareness of the support available to children as exacerbating the problem. A survey conducted on behalf of the Scottish Youth Parliament reinforces some of these points and identifies that young people in Scotland consider that information regarding mental health lacks credibility. They were also unaware of their rights in relation to mental health care. Many of the young people did not know where to locate information, including $70 \%$ of respondents who had experienced a mental health difficulty in the last year. Support, when offered, was often too late and at the point at which things had become critical. On a more positive note, services focusing specifically on the needs of young people were highly regarded by them (Scottish Youth Parliament, 2016).

The Scottish Government's ten year strategy (2017-2027) to improve mental health in Scotland (Scottish Government, 2017c) highlights the role of educators in creating a nurturing environment for children and young people in which they can 'feel safe, secure, resilient, confident, supported, and ready to learn' and stresses the importance of working across professional boundaries to support children and families.

We now turn our attention to the statistics which have been gathered systematically by Education Analytical Services of the Scottish Government on an annual basis to inform education policy.

\section{Exploring the relationships through Scottish Government Statistics}


The relationship between poverty and attainment is very clearly illustrated through Scottish Government statistics examining performance at the expected levels of the national curriculum - Curriculum for Excellence (CfE) (Scottish Government, 2017a); the former national surveys of literacy and numeracy (Scottish Government, 2016a, 2017e); and national qualifications in the senior phase of schooling (Scottish Government, 2017f, 2018c). There are four clear trends in evidence - a wide disparity in attainment according to Scottish Index of Multiple Deprivation (SIMD) ${ }^{\text {iv }}$ status; the gap in attainment extending as children progress through their schooling; the gap being widest at the higher levels of attainment; and, more positively, some tentative indications of the attainment gap beginning to close.

Of the 77,450 Scottish school pupils who fall within the lowest decile of the SIMD in 2016, around one third also intersect Additional Support Needs (ASN) and/or are Looked After Children (LAC) ${ }^{\mathrm{v}}$ (Scottish Government, 2017g). This implies that for some children the risks of under-achievement associated with poverty are compounded and intersectionality therefore is a key issue in understanding and addressing this problem.

Scottish Government statistics establish that the attainment of children with ASN and LAC, the latter of whom are particularly at risk of developing mental health problems (Scottish Government, 2017c), is also significantly below that of their peers (Scottish Government, 2018a, 2018f). For example, only $25.9 \%$ of those recorded as having ASN, in comparison to $41.9 \%$ of the 51,300 school leavers in $2016 / 17$, gained at least one qualification at level 6 (Scottish Highers) (Scottish Government, 2018d). However, even within the category of ASN, there are significant differences in academic attainment according to the type of need (Scottish Government, 2018f). Those most relevant to this paper are illustrated in chart 1 . 


\section{$\%$ of School Leavers by attainment according to ASN status 2016/2017}

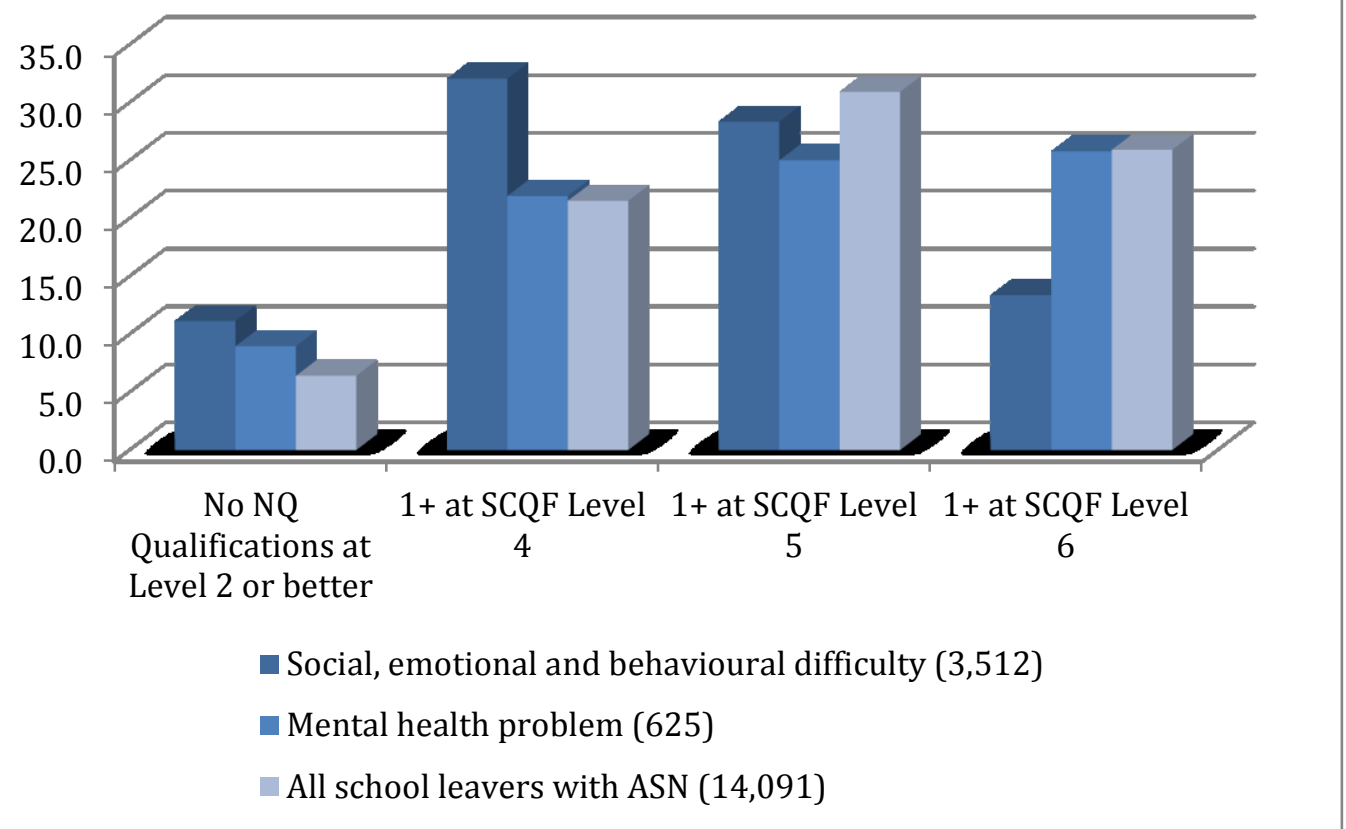

Chart 1: \% of school leavers according to ASN status achieving minimum SCQF qualifications (table A3.1 - a subset) (Scottish Government, 2018f)

What is of particular concern is the attainment of children recorded as having social, emotional and behavioural difficulties (SEBD) which, at level 6, is significantly below that of all children recorded with ASN. Children with SEBD represent the largest and fastest growing group of children recorded with ASN (Scottish Government, 2017d) (cc. chart 2). It has been established that SEBD may co-present with mental health problems and this is likely to be under-represented within Scottish Government statistics (Dyer \& Gregory, 2014; McAra \& McVie, 2010). 


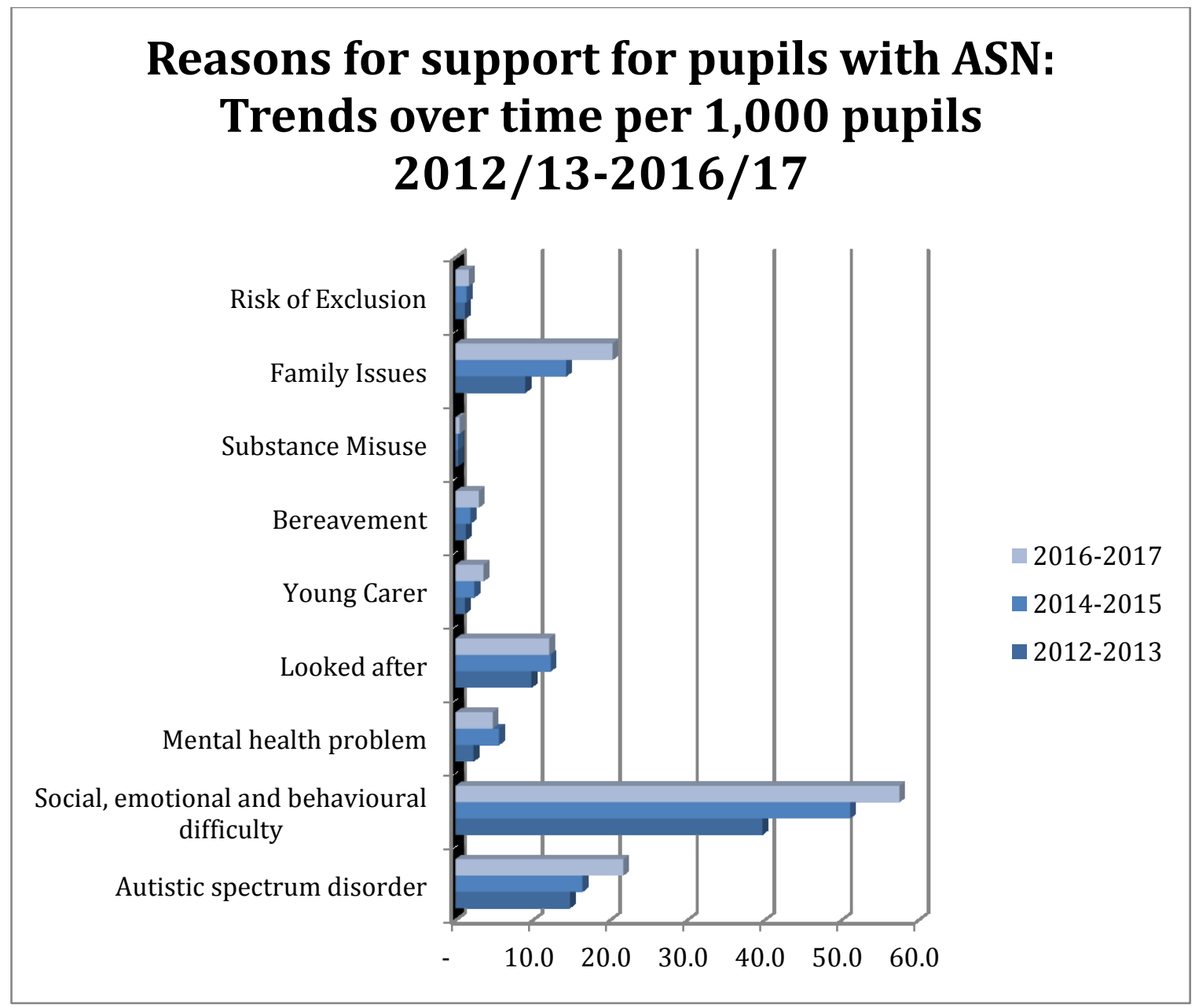

Chart 2: Reasons for support for pupils with ASN: trends over time per 1,000 pupils (table 1.8- subset) (Scottish Government, 2017d)

Pupils with ASN and Looked After Children are also over-represented in school exclusion statistics as are children living in poverty (Scottish Government, 2018a, 2018e). For example, there were 169 per 1,000 exclusions for LAC in 2016/2017 in comparison to 27:1,000 for all pupils (Scottish Government, 2018a). Exclusion from school has a range of potentially detrimental impacts including dislocation from the peer group and lack of access to the curriculum with the concordant risks of under-achievement, long term unemployment and poverty (McCluskey, Riddell, Weedon and Fordyce, 2016), in the process significantly impacting on pupil wellbeing.

The discussion to follow outlines the Scottish Government's response to the 
poverty-related attainment gap through the Scottish Attainment Challenge.

\section{The Scottish Attainment Challenge}

The Scottish Attainment Challenge (informed by insights gained from implementation of the London Challenge (Greaves, Macmillan, \& Sibieta, 2014)) was launched in 2015 by the Scottish Government to promote more equitable education outcomes and close the gap in attainment between rich and poor. It builds on 'Curriculum for Excellence' (CfE), the national curriculum; 'Getting it Right for Every Child' (GIRFEC), a multi-disciplinary approach to supporting children's welfare; and the 'Children and Young People (Scotland) Act (2014),' strengthening the rights of children and young people through legislative process. The policy is supported by funding ( $£ 750$ million in 2018) from the Scottish Government, channeled through a range of income streams directly to local authorities and schools ${ }^{\mathrm{vi}}$, the appointment of a team of National Attainment Advisors working directly with local authorities and schools; and by the National Improvement Framework and Hub (an electronic resource hosted on the Education Scotland website to support the work of schools in 'closing the gap'). It is important to note that education, health and aspects of fiscal policy are devolved functions of the Scottish Government and are distinctive from policy within the wider UK.

\section{Research focus}

Whilst the poverty-related attainment gap and the mental health and wellbeing of children and young people have risen to greater consciousness globally, there is a need to understand at a deeper level the relationships between the different components expressed within the title of the paper and the variables or drivers of 
these relationships which lie at the intersection in order to inform public policy at the international and national levels. Figure 1 sets out the nature of these relationships. This is pursued through a set of research questions which probe the nature of the relationships and seek to determine the variables that interact with each other to shape the subjective experience of the child or young person - how they feel and interpret their life experiences - understood through the lens of resilience and the risk and protective factors in their lives.

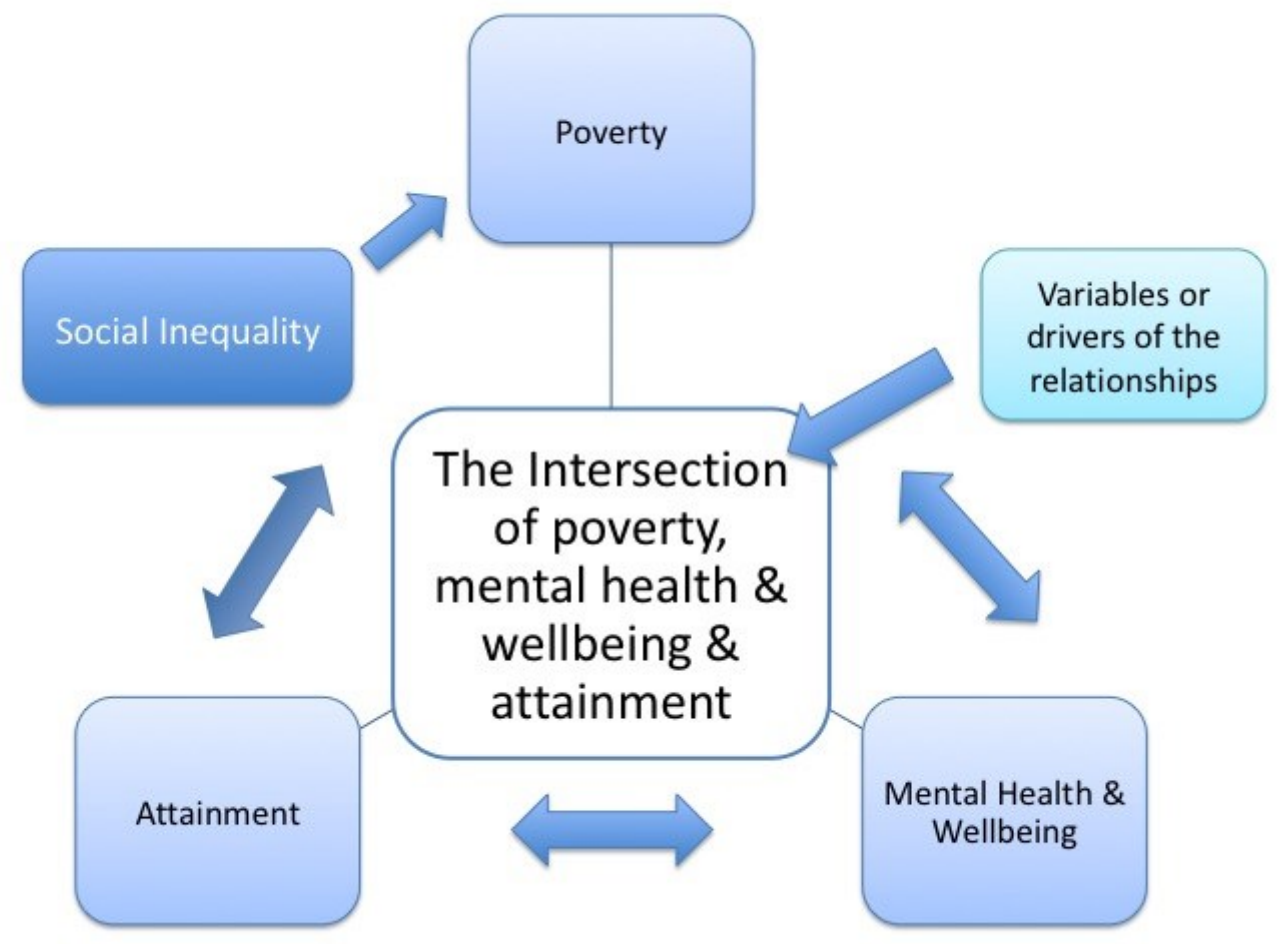

Figure 1: Illustration of conceptual framework of study design

\section{The concept of resilience}

The concept of resilience first came to prominence in the work of Garmezy who focussed on why some children were able to adapt more positively to stressors in their lives in comparison to others (Condly, 2006, Kolar, 2011). The concept has been used inconsistently across a range of disciplines (Kolar, 2011) and can be understood 
through both psychological and sociological lenses but common features relate to a capacity of the individual to stand firm in the face of adversity or stressors in their lives and 'bounce back' (Music, 2017). However, by its very nature, the concept is highly subjective as how does one define (and by who's judgement and by which criteria) 'adversity' or 'stressors' and what might constitute 'adapatability’?

For Olsson, Bond, Burns, Vella-Brodrick and Sawyer (2003), it is how the risk and protective factors at the individual (for example, traits such as sociability), social (related to the family and peer-network) and societal (the wider eco-systems with which the child interacts and the value structures associated with them) levels interact in the life of the child or young person which will determine the degree to which they will be resilient within a given context. However, whilst the authors acknowledge the impact which socio-economic status (as related to social class, ethnicity and gender) can play in this regard, there is insufficient account of the political dimension in shaping this context. Building on this body of work, Mowat (2015) crafts a model which brings to greater prominence this political dimension but also argues that resilience can only be understood fully when account is taken of the subjective experience of the child or young person - how they interpret their world, recognising also that it is a reciprocal process - individuals collectively shape cultural norms, values and the political context in time and place. 


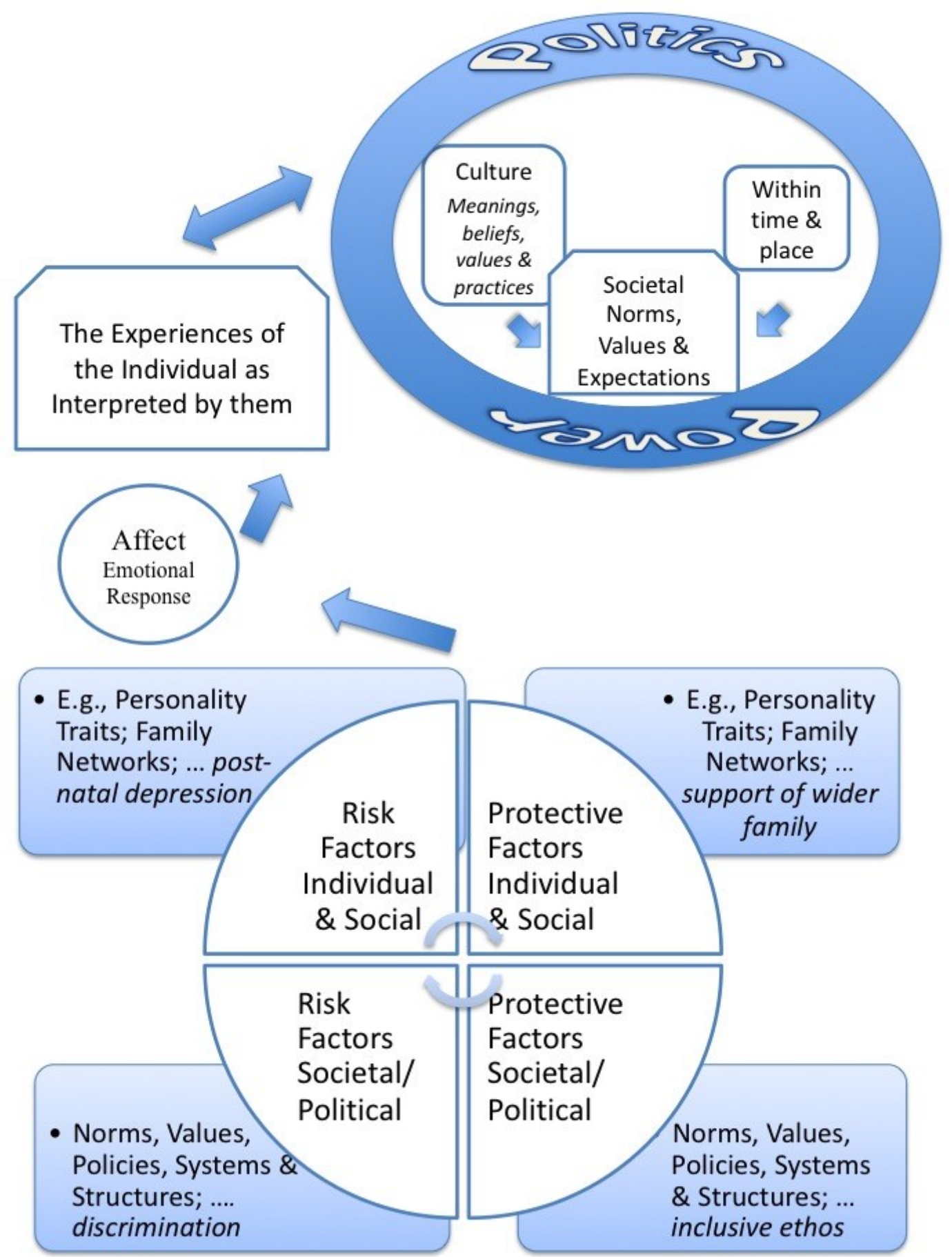

Figure 2: A bio-ecological model of resilience, building on Olsson et al. (2003) (Mowat, 2015)

It is this understanding of resilience which underpins the discussion with this paper, in keeping with ecological perspectives as described by Ungar and his colleagues (see 
Ungar, 2012a,b), deriving from Bronfenbrenner and Morris's bio-ecological theory (see Bronfenbrenner and Morris, 2006).

The impact of social inequality and poverty on the mental health and wellbeing of children and young people

This discussion will now explore more fully, from an international and then a Scottish perspective, the impact which social inequality and poverty exerts on the mental health and wellbeing of children and young people, having previously explored the link to attainment within the Scottish context.

\section{An International Perspective}

We have already established that the greater the income inequality within a society, the greater the negative impact on child wellbeing (UNICEF Office of Research, 2016; Wilkinson \& Pickett, 2010). Irrespective of family wealth, children living in countries with unequal income distribution are more prone to poorer health outcomes, poorer educational outcomes and other negative indicators (such as exposure to crime-ridden neighbourhoods) which persist over time (Wilkinson \& Pickett, 2010; World Health Organisation, 2016).

Children from less affluent backgrounds have the poorest health outcomes and this is more acute for adolescent girls than boys, a phase of development in which the psychosocial dimension is crucial (UNICEF Office of Research, 2016). Girls and children from poorer families rate their life satisfaction more poorly than do other children (OECD, 2017) but the gap in health and wellbeing associated with poverty is wider in Scotland amongst 15 year old boys than in any other country surveyed (World Health Organisation, 2016). 
There is an indirect relationship between poverty and poor subjective health (UNICEF Office of Research, 2016). Family affluence acts indirectly on children through social stratification, limiting access to material resources and creating stressors in families' and children's lives. Long-term poverty impacts negatively on infant and childhood mortality, poorer child health and incarceration (Cooper \& Mulvey, 2015).

According to WHO (World Health Organisation, 2016), children living in more affluent homes are less likely to be the victims of bullying, one of the most prevalent risk factors for mental health difficulties in children and adolescents with longterm consequences in terms of psychiatric and socio-economic difficulties in adulthood. This is particularly the case within the context of a digital age in which harassment and bullying are more insidious and pervasive in nature (Arseneault, 2018). Arseneault established that children living in poverty who have previously been bullied and who show vulnerability for developing mental health problems are particularly at risk in this respect.

\section{A Scottish perspective}

Socio-economic status is strongly correlated with mental health and wellbeing in children and adolescents (World Health Organisation, 2016) and this relationship is stronger in Scotland than in other European countries (Murphy, 2016). The Scottish Government's Health survey (which utilises the Warwick-Edinburgh Mental WellBeing Scale $^{\mathrm{vii}}$ ) establishes that, in the period 2012-2015, boys scored significantly higher than girls with regard to positive wellbeing and the score decreases for both boys and girls as they get older. The wellbeing scores do not differ significantly by area deprivation. In contrast, socio-economic factors are significant with regard to mental health problems in children and young people (under 19), except for those 
commonly experienced by all children, as was the case also for alcohol dependency (Mental Health Foundation, 2016).

The impact of financial vulnerability on the mother - brought about by worries about debt and managing family income - creates high levels of maternal emotional distress which impacts negatively on the wellbeing of younger children for whom this is more salient than comparisons with peers (Treanor, 2016). The 'Cost of the School Day' report (Glasgow Council, 2014) and the subsequent 'Cost of the School Day Toolkit' supports schools in identifying ways in which they can 'poverty proof' the school to alleviate these pressures (for example, access to computers through homework clubs).

Adverse Childhood Experiences Childhood abuse emerges as a major predictor of mental health issues in children. Drawing from the Scottish Health Survey (Scottish Government, 2015b), boys and children (aged 4-12) living in deprivation record higher scores on the Strength and Difficulties Questionnaire (SDQ) than other children with regard to borderline or abnormal difficulty scores. Children living in areas of deprivation are more than three times more likely to present in this way (Mental Health Foundation, 2016).

Building on the Adverse Childhood Experiences study conducted in the USA in 1995-1997 (see Felitti, Anda, \& Nordenberg, 1998), Couper and Mackie (2016) outline how exposure to abuse, neglect and household adversity can impact through life on a range of indicators related to physical and mental illness and mortality. These impact on the development of health-harming behaviours (such as drug usage); on education, income and employment; and expose the individual to the effects of 'toxic stress.' This, in turn, leads to physiological changes in brain structures which impede cognitive function and the capacity of the individual to respond in positive ways to 
stressors in their lives; to form and maintain positive relationships; and regulate emotions (Couper and Mackie, 2016). Living in poverty presents as a risk factor in terms of being exposed to ACEs (Marryat and Frank, 2019, National Health Service, 2017; Smith, 2018;) and the effect can be intergenerational (Smith, 2018). However, just as poverty and the stigma, discrimination and exclusion which can be associated with it may lead to ACEs, it could be argued that the corollary is also true.

Marryat and Frank (2019), drawing from data generated in the Growing up in Scotland (GUS) study (see discussion to follow), establish that $10 \%$ of eight-year olds within the study had experienced three or more ACEs. Being male, having younger mothers, mothers with lower educational qualifications and living in more deprived areas were associated with this statistic. Clear socio-economic patterns emerged whereas $1 \%$ of children living in households within the top income quintile had four or more ACEs, this contrasted with $10.8 \%$ in the lowest quintile. The study was not able to measure emotional abuse and neglect from the data available.

ACEs, however, have their limitations - they don't take account of the effect of a range of factors external to the home environment, such as the effects of bullying and forms of discrimination (Smith, 2018). It is proposed therefore that the scope of ACEs should be extended to cover a range of other adverse events in the life of the child (for example, bereavement of a parent), providing a more realistic representation of the reality of children's lives (Smith, 2018). It has been advocated that having a 'significant other' in the life of the child (National Health Service, 2017; Smith, 2018) and creating a nurturing environment within schools acts to mitigate the effects of toxic stress and promote resilience within the child (National Health Service, 2017). School relatedness/sense of belonging A range of commentators draw attention to the importance of a sense of belonging/relatedness/connectedness to school as being a 
key part in promoting positive mental health and wellbeing in children and young people (García-Moya, Brooks, Morgan, and Moreno, 2015, Lester and Cross, 2013, Prince, and Hadwin, 2013, and Riley, 2017) and the World Health Organisation argues that having strong social ties within the school environment leads to better attainment (World Health Organisation, 2016). Riley (2017) defines a 'sense of belonging' as 'a sense of somewhere you can feel confident that you will fit in and feel safe in your identity' (p. 4). For Riley, schools need to be places 'of opportunity, environments where all young people can flourish' (p. 6) and relationships lie at the heart of this, including positive relationships with teachers. Unfortunately, this is not the case for all children and young people and some find themselves disenfranchised 'looking in from outside:'

\begin{abstract}
The young people were on the periphery of school life, their learning experience often fragmented inconsistent and fragmented. Unable to conform in institutions which were alien to them, their behaviour could become inappropriate, challenging or even threatening. .. While school life offered them the possibilities of social networks which could be sources of friendship and fun, the experience was more likely to be one of sadness, rejection and loneliness (p. 35).
\end{abstract}

The youth justice system Those children and adolescents who have been caught up in the youth justice system are particularly vulnerable to mental health difficulties (Dyer \& Gregory, 2014). Children who have been excluded from school by age 12 are more likely by a factor of 4 to be in prison by age 22 (McAra \& McVie, 2010). Those most likely to be involved in violent offences (at age 15) are amongst the most vulnerable and victimised within the cohort (and most likely to be boys). Anti-social behaviour often co-presents with other mental health problems and at-risk behaviours. The authors advocate that intervention should be directed towards the critical stage in early-mid adolescence. 
Growing up in Scotland (GUS) longitudinal survey The GUS longitudinal study which commenced in 2005 focuses upon younger children from age 10.5 months onwards. The study draws from the perspectives of parents and older children over three cohorts ${ }^{\text {viii }}$.

Marryat, Thompson, Minnis, and Wilson (2015) establish a clear correlation between deprivation and the prevalence of social, emotional and behavioural difficulties (SEBD) ${ }^{\mathrm{ix}}$ in 3 year-old children living within the Greater Glasgow area in comparison to other children and particularly those from the most affluent homes. The authors suggest that the prevalence of SEBD in young children is mediated by parental stress brought about by poverty impacting on poor or harsh parenting; having fewer psychological resources to create a warm and loving home, leading to conduct problems and a lack of emotional regulation in children; intergenerational poverty; and adverse events (such as children witnessing violence in the home).

The authors establish that factors associated with deprivation (such as poor child health; developmental problems; low maternal education and health; family mental health/substance abuse; and lack of parental warmth) are associated with mental health difficulties in children, which may imply that the relationship between poverty and children's mental health is indirect and may be mediated by family stressors such as those above. Negative life experiences (such as illness, bereavement or less positive parenting) or lack of positive experiences impact directly upon children's subjective wellbeing (Marryat, Thompson, Minnis, and Wilson, 2015, p.5).

A further study (Marryat, Thompson, Minnis, \& Wilson, 2017), independent of GUS but carried out by the same team, found that on starting school, children within the Greater Glasgow area coming from the most deprived backgrounds evidence higher levels of mental health difficulties in comparison to their peers and 
these differences amplify over the first three years of schooling. After controlling for a range of variables, 'a school effect' was in evidence but the research team was unable to account for this variability. The implication of this is that schools can potentially make a difference but the mechanisms by which this occurs need greater clarification, highlighting the need for further research.

Parkes, Sweeting and Wight (2014) draw upon the accounts of 3,279 families of seven-year old children to examine family and school influences on children's social and emotional well-being. The study identified that the factors that impacted on mental health (for which family stressors related to deprivation were important (as identified also by Marryat et al. 2015)) were not necessarily associated with subjective wellbeing for which factors associated with negative affect (such as worry or pain), including family bereavement, illness or accident, or lack of positive affect (such as joy) were.

In a further study, examining children's subjective wellbeing from the perspectives of both children and parents (Parkes, Sweeting, \& Wight, 2016), the authors seek relationships between a range of early childhood factors (for example, low maternal education) and aspects of parenting (for example, home learning) at 4670 months, following this up with an examination of children's subjective wellbeing (liking of school, life satisfaction and supportive friendships) at 94 months (see figure 1, p. 1424). The findings suggest that early maternal distress, family poverty and remote location are predictive of children's later subjective wellbeing with the effects of maternal distress being conveyed indirectly through dysfunctional parenting, which was, in itself predictive of all three measures of subjective wellbeing with the strongest (negative) relationship being life satisfaction. 
The Scottish Government, bringing together the findings of 10 years of the GUS study (Scottish Government, 2015a) establishes that there are still stark inequalities in children's lives including risk behaviours that have long-term consequences for health and development. The report highlights the following as being important protective factors in the lives of young children:

- A rich learning environment;

- High quality early learning and childcare;

- Being born to an older mother;

- Improving the physical and mental health of mothers;

- Supporting parenting skills (p.10).

The implications of this important study are that children's mental health, development and subjective wellbeing cannot be considered in isolation of the environmental factors which impinge upon family life, and support for families, in particular, mothers, is crucial in addressing the stark inequalities between children brought up in the most and least deprived homes.

\section{Synthesis and Discussion}

So, what have we learned to inform the research questions underpinning the study? In examining the relationships which have emerged through this discussion (whether direct or indirect) what has emerged is complexity. An extensive range of risk and protective factors interact in complex ways within the lives of children and young people, acting to mediate the aforementioned relationships. These have been classified in Appendix 1 (see supplemental material). It should be noted that some factors (or variables) may appear in more than one category. For example, 'An inclusive school ethos which affirms the child or young person' may impact directly 
on the subjective experience of the child or young person (individual level) but it is also representative of the quality of the social relationships within the school (social level) and of the school's policies and practice (which reflect societal norms and values and the school's vision and values), which, in turn, are influenced and shaped by public policy (political level). What has also become evident is that, whilst there is value in examining the problem from the perspective of both risk and protective factors, this may serve to mask the complexities in that many variables may lie on a dynamic continuum. At which point does 'nurturing parenting' become 'good enough parenting' and then 'dysfunctional parenting?' (and by who's judgement, by which criteria and underpinning values, and can this be held to be stable and to apply in all circumstances and contexts?). This highlights the highly subjective nature of the concepts.

The relationships (both direct and indirect) identified from the analysis of the literature in relation to mental health, wellbeing, attainment/achievement and life opportunities categorised against income inequality, family affluence/poverty, socioeconomic status and deprivation/SIMD status are set out in Appendices $2 \& 3$ and are mapped out in Appendix 4 (see supplemental material).

The key finding is that economic inequality at a societal level underpins and acts as a driver for all of the other relationships, impacting on family affluence/poverty, social stratification and inequalities. This, in turn, leads to stressors in the home associated with deprivation (as described by Cooper \& Mulvey, 2015, Marryat et al., 2015 and Treanor, 2016), financial vulnerability and high levels of maternal distress which then affects the quality of parenting, exposing children to a higher risk of ACEs (such as domestic violence), impaired cognitive function and developmental problems and acting on their wellbeing/subjective wellbeing, leading 
to mental health disorders (such as anxiety and depression), SEBD and conduct problems. The last of these make it more likely that children and young people will be excluded from school which, as described by a range of commentators (see Dyer and Gregory, 2014, McAra, aand McVie, 2010 and McCluskey et al., 2016), heightens their chances of being in contact with the criminal justice system, impacts on the quality of their interpersonal relationships and the quality of the learning experience and, ultimately, their educational opportunities and prospects for employment, perpetuating the cycle of deprivation and intergenerational poverty.

\section{Implications and conclusions}

It will be evident from the preceding discussion that the problem needs to be understood holistically and to recognise that the solution cannot rest with schools alone, whilst acknowledging the important role they play. Without a strong infrastructure around schools, communities and families and appropriate age-related services, available at point of need, and without addressing fundamental inequalities in society through economic and public policy, the poverty-related attainment gap is unlikely to be addressed to any significant extent. This presents as a major challenge to governments as resources are not infinite and need to be deployed in ways which are economical, efficient and also sustainable, in keeping with UNICEF's goals for sustainability (UNICEF Office of Research, 2017).

The Scottish Government is addressing these wider issues through the Child Poverty Strategy for Scotland (Scottish Government, 2014); the Child Poverty (Scotland) Act (Scottish Government, 2017b) and subsequent Delivery Action Plan 2018-2022 (Scottish Government, 2018b), the main thrust of which is to aim to have fewer than $10 \%$ of children living in relative poverty and fewer than $5 \%$ in absolute poverty by 2030 . However, there are concerns that pressures on local authority 
budgets and UK welfare reform will act to counteract efforts to reduce childhood poverty (Freeman, 2017) with local authorities 'robbing Peter to pay Paul'.

In a highly critical report (Alston, 2018), Professor Philip Alston, United Nations Special Rapporteur on extreme poverty and human rights, argues that the UK Government's welfare agenda has been driven by 'radical social engineering:'

... despite the rhetoric of the UK government, welfare reforms have been driven not primarily by economic imperatives (in the name of austerity) but by radical social engineering leaving 'millions of children ... locked into a cycle of poverty from which most will have great difficulty escaping (p. 2).

The Scottish Government is committed to eradicating the poverty-related attainment gap ${ }^{\mathrm{x}}$, but the funding streams attached to the Scottish Attainment Challenge bring with them increased accountability with schools having to evidence through data the impact of their improvement agendas. It could be argued that by shifting accountability and responsibility to schools for 'closing the gap,' emphasis is being directed away from the systemic inequalities which create the conditions under which families live in poverty and the stressors associated with it.

This is paralleled at an international level by the ascendancy of the OECD, reflected in high-stakes testing régimes such as PISA, PIRLS and TIMSS and leading to what some would describe as the marketisation of education (Ball, 2015; Brunila, 2011) and a culture of performativity, residing within a neo-liberal agenda (Clapham, Vickers, \& Eldridge, 2016, D’Agnese, 2018). According to D’Agnese, 'Students .. relate to one another in a standardised arena, striving for the same things, competing for "better jobs" and "better lives"' (p.4) Within such a context, there has been a 'subtle change in emphasis' in which schools, driven by market forces, value some pupils more than others on the basis of the 'added value' which they bring to the school, reflecting a move away from a focus on meeting student needs to performance 
- what the student contributes to the school rather than what the school contributes to the student (Apple, 2001).

Whilst the comprehensive system of schooling in Scotland, whereby children attend their neighbourhood schools, should mitigate against the impact of this neoliberal agenda, the reality is that middle-class families have the financial capital to locate in areas of 'high-performing' schools (Murphy, 2014), exacerbated by the effects of parental choice legislation (Croxford, 2015), creating, in effect, a two-tier school system, a phenomenon observed also in the wider UK and the USA (Riley, 2017). The OECD (2018a) observes that disadvantaged children attending schools with the highest concentration of children coming from disadvantaged backgrounds had the poorest educational outcomes and prospects of social mobility.

As previously discussed, it is evident that some children, specifically those who intersect poverty, ASN (and, in particular those with SEBD) and LAC are at a particularly high risk of marginalisation and poor educational outcomes. From the perspective of the author, there has been a fracturing of educational policy in Scotland which positions the inclusion agenda as being distinct from that of 'closing the gap.' Inclusion, and, in particular, the removal of barriers to participation and learning, needs to be put at the heart of the Scottish Attainment Challenge, whilst maintaining still a broader focus on policy, systems, structures, school ethos, leadership, partnerships, curriculum, pedagogy and embracing diversity.

On a note of caution, whilst the increasing awareness of the impact of ACEs on children and young people in Scotland is to be welcomed (reflected in public policy), there is a danger in approaching this body of work uncritically. Large-scale surveys can be very valuable in identifying trends, correlations and causality but, when applied to the level of the individual child or family, there is a danger of false 
assumptions being made as the data revealed is broad and does not drill down to the specifics that relate to each individual. When the child is then viewed through the prism of ACEs, leading to the potential for labelling and the stigmatisation which may arise from it, this could then become a self-fulfilling prophesy. Meantime, there may be other children or young people who do not fall within the ACEs category but who, for other reasons, may present with mental health difficulties which could be overlooked.

The ACEs methodology takes no account of culture, context or situation; applies equal weighting to adverse circumstances which may have profoundly different effects and impact; and takes little or no account of the protective factors in children's lives which may shield them from the potentially harmful effects. In its extended form, it also risks pathologising what may be very painful, but normal, aspects of life, for example, bereavement, and positions the individual as someone lacking in agency, requiring therapeutic intervention. Within this paradigm, resilience (framed as a psychological construct and seen as the solution) is positioned as an inherent trait or capacity of the individual which is stable in all contexts and circumstances (you either have it or you don't) rather than a complex interaction between the child and the environment (Condly, 2006), in keeping with ecological understandings of the concept (see Mowat, 2015, Olsson et al, 2003, Rutter, 2012 and Ungar, 2012a \& b).

Finally, it is important not to focus solely on poverty in isolation of the other ways in which children and young people can be marginalised in their lives, recognising intersectionality. This implies an holistic focus on the needs of the child or young person, examining their lives 'in the round' through the various networks within which the child or young person interacts, supported by strong inter- 
professional partnerships in which there are shared understandings between professionals based on inclusive values. A major challenge is to balance the adoption of more universal approaches in meeting the needs children and young people with those more directed towards the needs of the individual and to ensure that professionals are supported in their role and are in receipt of high quality training in working with communities, families, children and young people.

All of the above is dependent on high quality leadership at all levels of the system and, as argued by Ainscow and Sandill (2010), on a recognition that, in seeking to improve student outcomes, the starting point lies with changing the behaviours of adults, enhancing their capacity to imagine what might be possible and increasing their sense of accountability to bring it about. This means engaging at a deep level and challenging the values, beliefs, attitudes, assumptions and prejudices of all who work to support children, young people, families and communities and those of the policy community. This work needs to be supported through the research community, working across inter-professional boundaries and academic fields to break down the silos which prevent insights gained in one field of enquiry informing others - the problem and its solution are too complex to be understood through a single lens.

\section{Further developments}

This body of work is being further developed through a partnership between four universities, two local authorities (working with early adolescents to explore their sense of belonging to school) and five $3^{\text {rd }}$ sector organisations, supported by the Scottish Universities Insight Institute, the outcome of which will be a series of research briefs for practitioners, parents and policy makers. https://www.scottishinsight.ac.uk/Programmes/OpenCall201819/PEAW.aspx 


\section{References}

Ainscow, M., \& Sandill, A. (2010). Developing inclusive education systems: the role of organisational cultures and leadership. International Journal of Inclusive Education, 14(4), 401-416.

Ainscow, M., Dyson, A., Goldrick, S., \& West, M. (2012). Making schools effective for all: rethinking the task. School Leadership \& Management: Formerly School Organisation, 32(3), 197-213.

Alston, P. (2018). Statement on Visit to the United Kingdom, by Professor Philip Alston, United Nations Special Rapporteur on extreme poverty and human rights. London. Retrieved from https://www.ohchr.org/Documents/Issues/Poverty/EOM_GB_16Nov2018.pdf

Apple, M. W. (2001). Comparing Neo-liberal Projects and Inequality in Education. Comparative Education, 37(4), 409-423.

Arseneault, L. (2018). Annual Research Review: The persistent and pervasive impact of being bullied in childhood and adolescence: implications for policy and practice. The Journal of Child Psychology and Psychiatry, 59(4), 405-421.

Ayre, D. (2016). Poor Mental Health: The links between child poverty and mental health problems. Keighley, Bradford, UK.: The Children's Society.

Ball, S. J. (2015). Education, governance and the tyranny of numbers. Journal of Education Policy, 30(3), 299-301.

Bronfenbrenner, U., \& Morris, P. A. (2006). The bioecological model of human development. In R. M. Lerner (Ed.), Handbook of Child Psychology: Theoretical Models of Human Development (6th ed., Vol. 1, pp. 793-828). New Jersey: Wiley.

Brunila, K. (2011). The Projectisation, Marketisation and Therapisation of Education. European Educational Research Journal, 10(3), 421-432.

Bruckauf, Z. (2017). Adolescents' Mental Health: Out of the shadows. Evidence on psychological well-being of 11-15-year-olds from 31 industrialized countries Innocenti Research Brief (Vol. 2017-12). Florence, Italy.

Clapham, A., Vickers, R., \& Eldridge, J. (2016). Legitimation, performativity and the tyranny of a 'hijacked' word. Journal of Education Policy, 31(6), 757-772.

Condly, S., J. (2006). Resilience in Children: A Review of Literature With Implications for Education. Urban Education, 41, 211-236.

Cooper, B. S., \& Mulvey, J. D. (2015). Connecting Education, Welfare, and Health for American Families. Peabody Journal of Education, 90(5), 659-676. doi: 10.1080/0161956X.2015.1087776

Couper, S., \& Mackie, P. (2016). 'Polishing the Diamonds': Addressing Adverse Childhood Experiences in Scotland: National Health Service.

Croxford, L. (2015). Inequalities. In D. Murphy, L. Croxford, C. Howieson \& D. Raffe (Eds.), Everyone's Future: Lessons from fifty years of Scottish comprehensive schooling (pp. 110138). Stoke-on-Trent: Trentham Books.

Currie, C., Whitehead, R., Van der Sluijs, W., Currie, D., Rhodes, G., Neville, F., \& Inchley, J. (2015). Health Behaviour in School-aged Children: World Health Organization Collaborative CrossNational Study(HBSC): findings from the 2014 HBSC survey in Scotland. University of St Andrews: Child and Adolescent Health Research Unit (CAHRU).

D'Agnese, V. (2018). Reclaiming Education in the Age of PISA: Challenging OECD's Educational Order London: Routledge.

Dyer, F., \& Gregory, L. (2014). Mental Health Difficulties in the Youth Justice Population: Learning from the first six months of the IVY project. Glasgow: Centre for Youth and Criminal Justice.

Felitti, V., Anda, R., \& Nordenberg, D. (1998). Relationship of childhood abuse and household dysfunction to many of the leading causes of death in adults: The Adverse Childhood Experiences (ACE) study. American Journal of Preventative Medicine, 14(4), 245-258.

Freeman, T. (2017, 10/02/2017). Child poverty bill published by Scottish Government, News item. Holyrood. Retrieved from file:///Users/jis04102/Desktop/Poverty\%20paper/Scottish\%20Government $\% 20$ Policies $\% 20 \&$ \%20Statistics/Child\%20Poverty\%20Bill.webarchive

García-Moya, I., Brooks, F., Morgan, A., \& Moreno, C. (2015). Subjective well-being in adolescence and teacher connectedness: A health asset analysis. Health Education Journal, 74(6), 641 654.

Glasgow Council. (2014). Cost of the School Day Seminar Report. Glasgow: Child Poverty Action Group.

Goleman, D. (1996). Emotional Intelligence: why it can matter more than IQ. London: Bloomsbury. 
Gomendio, M. (2017). Empowering and Enabling Teachers to Improve Equity and Outcomes for all. International Summit on the Teaching Profession. Paris: OECD.

Goodman, R. (2006). The Strengths and Difficulties Questionnaire: A Research Note. Journal of Child Psychology and Psychiatry, 38(5), 581-586.

Greaves, E., Macmillan, L., \& Sibieta, L. (2014). Lessons from London schools for attainment gaps and social mobility. London: Social Mobility and Poverty Commission.

Gutman, L., Joshi, H., Parsonage, M., \& Schoon, I. (2015). Children of the New Century: Mental Health findings form the Millennium Cohort Study. London: UCL Institute of Education.

Jesson, J., Matheson, L., \& Lacey, F., M. (2011). Doing your Literature Review: Traditional and Systematic Techniques. London: SAGE publications.

King, N., \& Horrocks, C. (2010). Interviews in Qualitative Research. London: SAGE.

Kolar, K. (2011). Resilience: Revisiting the Concept and its Utility for Social Research. International Journal of Mental Health Addiction, 9, 421-433.

Layard, R., \& Dunn, J. (2009). A Good Childhood: Searching for Values in a Competitive Age. London: Penguin Books.

Lester, L., Waters, S., \& Cross, D. (2013). The Relationship Between School Connectedness and Mental Health During the Transition to Secondary School: A Path Analysis. Australian Journal of Guidance and Counselling, 23(2), 157-171.

Marryat, L., \& Frank, J. (2019). Factors associated with adverse childhood experiences in Scottish children: a prospective cohort study BMJ Paediatrics Open.

Marryat, L., Thompson, L., Minnis, H., \& Wilson, P. (2015). Exploring the social, emotional and behavioural development of preschool children: is Glasgow different? International Journal for Equity in Health, 14(3), 1-16. doi: 10.1186/s12939-014-0129-8

Marryat, L., Thompson, L., Minnis, H., \& Wilson, P. (2017). Primary schools and the amplification of social differences in child mental health: a population-based cohort study. Journal of Epidemiology \& Community Health Education Journal, 72(1), 1-7. doi: 10.1136/jech-2017208995

McAra, L., \& McVie, S. (2010). Youth crime and justice: Key messages from the Edinburgh Study of Youth Transitions and Crime. Criminology and Criminal Justice, 10(2), 179-209.

McCluskey, G., Riddell, S., Weedon, E., \& Fordyce, M. (2016). Exclusion from school and recognition of difference. Discourse: Studies in the Cultural Politics of Education, 37(4), 529-539. doi: 10.1080/01596306.2015.1073015

Mental Health Foundation. (2016). Mental Health in Scotland: Fundamental Facts 2016. London/Glasgow: Mental Health Foundation.

Mental Health Foundation. (2015, July 20). What is wellbeing, how can we measure it and how can we support people to improve it? [Blog post]. Retrieved from

https://www.mentalhealth.org.uk/blog/what-wellbeing-how-can-we-measure-it-and-how-canwe-support-people-improve-it

Moore, A., \& Clarke, M. (2016). 'Cruel optimism': teacher attachment to professionalism in an era of performativity. Journal of Education Policy, 31(5), 666-677.

Mowat, J. G. (2015). Towards a new conceptualisation of marginalisaion. European Educational Research Journal, 14(5), 454-476.

Murphy, D. (2014). Schooling Scotland: Education, Equity and Community. Edinburgh: Argyll Publishing.

Murphy, R. (2016). Child and Adolescent Mental Health -Trends and Key Issues SPICe Briefing. Edinburgh.

Music, G. (2017). Nurturing Natures: Attachment and Children's Emotional, Sociocultural and Brain Development (2nd ed.). London: Routledge.

National Health Service. (2017). Tackling the attainment gap by preventing and responding to Adverse Childhood Experiences (ACEs). Edinburgh.

NHS Information Division. (2017). Child and Adolescent Mental Health Services: Waiting Times in NHS Scotland: Quarter ending 31 December 2016. Edinburgh: NHS.

Nussbaum, M. C. (2011). Creating capabilities: the human development approach. Massachusetts and London: Harvard University Press.

OECD. (2017a). Are students happy? PISA 2015 Results: Students' Well-being. Vol 3. PISA in Focus (Vol. 71). Paris: OECD.

OECD. (2018a). Equity in Education: Breaking Down Barriers to Social Mobility. Paris: OECD Publishing.

OECD. (2018b). Trends Shaping Education Spotlight 14: Good vibrations: Students' well-being. Paris: OECD. 
Olsson, C., A., Bond, L., Burns, J., M., Vella-Brodrick, D., A., \& Sawyer, S., M. (2003). Adolescent resilience: a concept analysis. Journal of Adolescence, 26, 1-11.

Parkes, A., Sweeting, H., \& Wight, D. (2014). Growing up in Scotland. Family and school influences on children's social and emotional well-being. Edinburgh: Scottish Government.

Parkes, A., Sweeting, H., \& Wight, D. (2016). What shapes 7-year-olds' subjective well-being? Prospective analysis of early childhood and parenting using the Growing Up in Scotland study. Social Psychiatry and Psychiatric Epidemiology, 51, 1417-1428.

Patalay, P., \& Fitzsimons, E. (2018). Mental ill-health and wellbeing at age 14 - Initial findings from the Millennium Cohort Study Age 14 Survey. London: Centre for Longitudinal Studies.

Patel, V., Sheckar, S., Lund, C., Thornicroft, G., Baingana, F., \& Bolton, P. (2018). The Lancet Commission on global mental health and sustainable development. The Lancet Commissions, 392(10157), 1553-1598.

Prince, E. J., \& Hadwin, J. (2013). The role of a sense of school belonging in understanding the effectiveness of inclusion of children with special educational needs. International Journal of Inclusive Education, 17(3), 238-262.

Rutter, M. (2012). Resilience: Causal Pathways and Social Ecology. In M. Ungar (Ed.), The Social Ecology of Resilience: A Handbook of Theory and Practice (pp. 33-42). New York: Springer.

Riley, K. (2017). Place, belonging and school leadership: researching to make the difference. London: Bloomsbury Academic.

Schleicher, A. (2014). Equity, Excellence and Inclusiveness in Education: Policy Lessons from Around the World: Background report for the 2014 International Summit of the Teaching Profession. Paris, France: OECD.

Scottish Government. (2014). Child Poverty Strategy for Scotland: Our approach 2014-2017. Edinburgh: Scottish Government. Retrieved from https://www2.gov.scot/Publications/2014/03/5304

Scottish Government. (2015a). Growing up in Scotland: Tackling inequalities in the early years: Key messages from 10 years of the Growing Up in Scotland study. Paper presented at the Growing up in Scotland Event 06/10/2015, Edinburgh

Scottish Government. (2015b). The Scottish Health Survey: 2015 edition, volume 1, main report. Retrieved from http://www.gov.scot/ Publications/2016/09/2764/downloads.

Scottish Government. (2016a). Scottish Survey of Literacy and Numeracy 2015: Numeracy. Retreived from https://www.gov.scot/publications/scottish-survey-literacy-numeracy-2015-numeracy/

Scottish Government. (2016b). Supporting Children's Learning: Implementation of the Education (Additional Support for Learning) (Scotland) Act 2004. Retrieved from http://www.gov.scot/Publications/2016/03/3603.

Scottish Government. (2017a). Achievement of Curriculum for Excellence (CfE) Levels 2016/17. Retrieved from http://www.gov.scot/Publications/2017/12/5300

Child Poverty (Scotland) Act 2017 (2017b). Retreived from http://www.legislation.gov.uk/asp/2017/6/contents/enacted

Scottish Government. (2017c). Mental Health Strategy: 2017-2027. Retreived from https://www.gov.scot/publications/mental-health-strategy-2017-2027/

Scottish Government. (2017d). Pupil Census 2017 Supplementary Data. Retreived from https://www2.gov.scot/Topics/Statistics/Browse/School-Education/PubPupilCensus

Scottish Government. (2017e). Scottish Survey of Literacy and Numeracy 2016: Literacy. Retreived from https:/www.gov.scot/publications/scottish-survey-literacy-numeracy-2016-literacy/

Scottish Government. (2017f). Summary Statistics for Attainment, Leaver Destinations and Healthy Living No. 7: 2017 Edition: Supplementary Data. Retrieved from http://www.gov.scot/stats/bulletins/01279.

Scottish Government. (2017g). Summary Statistics for schools in Scotland No:7 - 2016 edition. Retrieved from http://www.gov.scot/Topics/Statistics/Browse/SchoolEducation/PubPupilCensus.

Scottish Government. (2017h). Supporting Children's Learning Statutory Guidance on the Education (Additional Support for Learning) Scotland Act 2004 (as amended) Code of Practice (Third Edition) 2017. Retrieved from http://www.gov.scot/Publications/2017/12/9598.

Scottish Government. (2018a). Education Outcomes for Looked After Children 2016/17. Retrieved from https://beta.gov.scot/publications/education-outcomes-scotlands-looked-children-2016$17 /$.

Scottish Government. (2018b). Every child, every chance: The Tackling Child Poverty Delivery Plan 2018-2022. Retrieved from https://http://www.gov.scot/Resource/0053/00533606.pdf. 
Scottish Government. (2018c). Initial Destinations of Senior Phase School Leavers, No. 2: 2018 Edition. Retrieved from https://www.gov.scot/publications/initial-destinations-senior-phaseschool-leavers-2-2018-edition/

Scottish Government. (2018d). Pupils in Scotland 2017 (Supplementary Statistics from the 2017 Pupil Census). Retrieved from https://www2.gov.scot/Topics/Statistics/Browse/School Education/dspupcensus/dspupcensus 17

Scottish Government. (2018e). School Exclusions 2016/2017. Retrieved from https://www2.gov.scot/Topics/Statistics/Browse/SchoolEducation/exclusiondatasets/exclusionsdataset2017

Scottish Government. (2018f). Summary Statistics for Attainment, Leaver Destinations and Healthy Living No. 8: 2018 Edition. Retrieved from https://http://www.gov.scot/Publications/2018/06/6856.

Scottish Youth Parliament. (2016). Our generation's epidemic: Young people's awareness and experience of mental health information, support, and services. Edinburgh.

Smith, M. (2018). Capability and adversity: reframing the "causes of the causes" for mental health. Palgrave Communications, 4(13), 1-5.

The Children's Society. (2018). The Good Childhood Report 2018. London.

Treanor, M. (2016). The effects of financial vulnerability and mothers' emotional distress on child social, emotional and behavioural well-being: a structural equation model. Sociology, 50(4), 673-694.

Ungar, M. (2012a). Social Ecologies and Their Contribution to Resilience. In M. Ungar (Ed.), The Social Ecology of Resilience: A Handbook of Theory and Practice (pp. 13-32). New York: Springer.

Ungar, M. (Ed.). (2012). The Social Ecology of Resilience: A Handbook of Theory and Practice. New York: Springer.

UNICEF Office of Research. (2010). The children left behind: A league table of inequality in child well-being in the world's rich countries. Innocenti Report Card 9. UNICEF Innocenti Research Centre, Florence.

UNICEF Office of Research. (2016). Fairness for Children: A league table of inequality in child wellbeing in rich countries. Innocenti Report Card 13. Florence: UNICEF Office of Research.

UNICEF Office of Research. (2017). Building the Future Children and the Sustainable Development Goals in Rich Countries. Innocenti Report Card 14. Florence: UNICEF Office of Research.

Wilkinson, R., \& Pickett, K. (2010). The Spirit Level: Why equality is better for everyone. London: Penguin Books.

Wolff, J., Lamb, E., \& Zur-Szpiro, E. (2015). A philosophical review of poverty. York: Joseph Rowntree Foundation. Retrieved 10/02/2019 from https://www.jrf.org.uk/report/philosophical-review-poverty

World Health Organisation. (2013). Mental Health Action Plan 2013 - 2020. Geneva, Switzerland.

World Health Organisation. (2016). Growing up unequal: gender and socioeconomic differences in young people's health and well-being: Health Behaviour in School-Aged Children (HBSC) Study: International Report from the 2013/2014 survey (Vol. Health Policy for Children and Adolescents, no. 7). Denmark.

\section{Notes}

${ }^{\mathrm{i}}$ nutrition, clothing, educational resources, leisure activities, social activities, information access, or housing

${ }^{\text {ii }}$ Socioeconomic status is the social standing or class of an individual or group. It is often measured as a combination of education, income and occupation (American Psychological Association) https://www.apa.org/topics/socioeconomic-status/

iii The Strengths and Difficulties Questionnaire (known also as the Goodman Scale) constitutes 25 psychological attributes divided between 5 scales measuring emotional symptoms; conduct problems; hyperactivity/inattention; peer problems; and pro-social behaviour to be rated by parents and teachers (Goodman, 2006). There are various modifications and adaptations relating to it to serve different purposes.

iv The Scottish Index of Multiple Deprivation is devised from a synthesis of 39 data sources which span across domains such as income, employment, health, education, housing, access and crime. 


\footnotetext{
${ }^{\mathrm{v}}$ This was formerly designated Looked After and Accommodated (LAAC)

${ }^{\text {vi }}$ In the current financial year, $£ 120$ million is directed towards the Pupil Equity Fund; $£ 50$ million to the Challenge Authorities and Schools Programme; $£ 8$ million to Care Experienced Children and Young People; and additional funding directed towards National programmes such as the establishment of Regional Collaboratives (https://www.gov.scot/policies/schools/pupil-attainment/)

${ }^{\text {vii }}$ A 14-item scale which captures feelings and thoughts to enable the monitoring of mental wellbeing in the general population http://www2.warwick.ac.uk/fac/med/research/platform/wemwbs/ viii https://growingupinscotland.org.uk/about-gus/study-design-and-methodology/

${ }^{i x}$ Whilst the term Social, Emotional and Behavioural Needs (in keeping with the Support for Children's Learning Code of Practice (Scottish Government, 2017h)) is more commonly used in Scotland, for reasons of consistency, the term SEBD is used throughout the paper as this is the term adopted in Scottish Government Statistics

${ }^{\mathrm{x}}$ Speech given by First Minister, Nicola Sturgeon (09/02/2015) to St Joseph's Primary, Dundee. https://news.gov.scot/speeches-and-briefings/first-minister-speech-on-scottish-attainment-challenge
} 